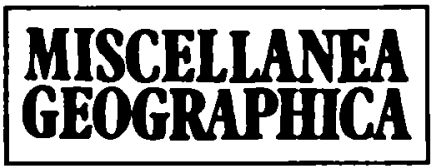

WARSZAWA 1992 Vol. 5

Andrzej Lisowski

\title{
THE EFFECT OF WINTER HAZARDS ON ROAD TRANSPORTATION IN POLAND
}

A severe winter is an environmental hazard that is difficult to define univocally in the physical as well as social categories. Most frequently a frosty and snowy winter is considered as severe winter in the light of the particular thermal and precipitation characteristics (Paczos 1982). However, disturbances in social life are a result of complex conditions: physical (frost, snow, gales) as well as social (meteorological shield, sensitiveness of the applied technology to the low temperatures, organization of preventive and immediate activities to alleviate effects of the severe winter).

This paper is an attempt to identify a degree of disturbance of social life in Poland in the winter seasons in the years 1960-1990 on the example of road transportation, which is the most sensitive sphere of the socio-economic life. The disruptions in the road traffic are a phenomenon which indirectly interferes in many other activities of man.

A winter maintenance of the state and voivodship (local) roads is a routine job of the road services operating in the 17 road regions. In the years 1961-1989 the cost of winter maintenance of roads (i.e. snow removal and combat against frost-glazing) amounted to $13.4 \%$ of overall costs of the maintenance of roads throughout the year (Fig. 1). A share in the cost of state roads maintenance showed an increasing trend up to 1980 , and was considerably declining in the $1980 \mathrm{~s}$. The increase in the costs was a consequence of the growing number of vehicles and intensity of road traffic also in the winter, in particular in the 1970 s and the decline is related to the stabilization of the level of intensity of road traffic (1980-1988) and to the curtailment of expenditure for the winter maintenance of roads in the face of economic crisis. Most funds have been spent for the winter maintenance of roads in the years 1968-1970 and 1978-1981, with maximum in $1979(24.6 \%)^{1}$.

\footnotetext{
${ }^{1}$ In relation to the net national product, a distribution of expenditures for winter maintenance of the state roads is similar. These expenditures amounted on the average to $0.098 \%$ of the net national product, with maximum in $1979(0.189 \%)$. In the years 1976-1989 the costs of the winter maintenance of the state and local roads totalled $0.154 \%$ of the GNP.
} 


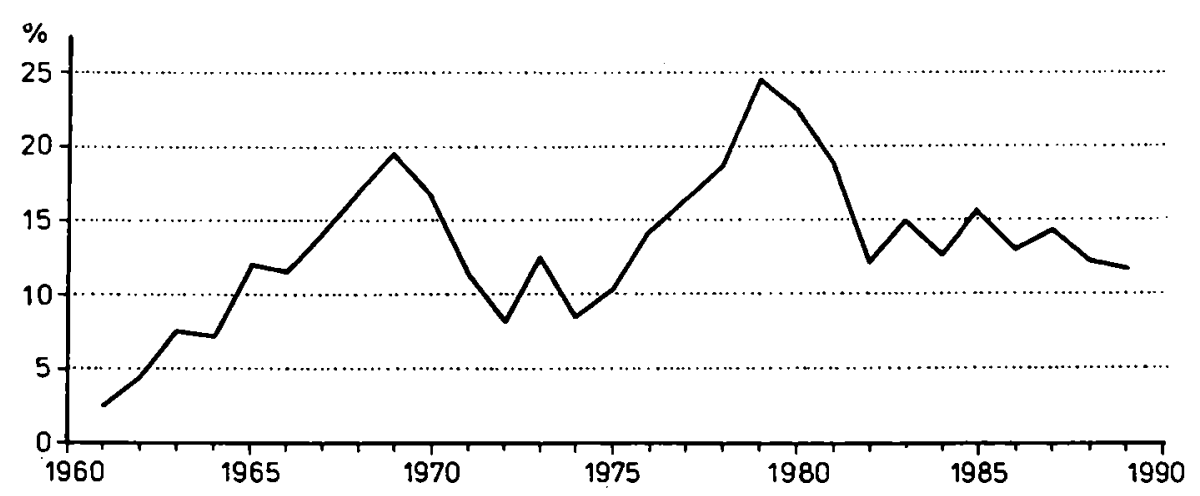

Fig. 1 Share of winter road maintenance costs in total yearly road maintenance costs in Poland 1961-1989

Depending on the importance of roads, they are divided into three categories. Initially, efforts were made to fight winter frost-glazing and to remove snow on the roads of all categories which usually exceeded the costs envisaged. Financial problems compelled the road services, however, to apply intervention system in the snow removal from the roads of the 2nd and 3rd category, and in the 1989/90 season combat against the frost-glazing on the roads of the 3rd category was practically given up by the state road services. This decision caused protests of the local communities.

In total, $66 \%$ of the costs of road maintenance in winter goes for combating the winter glazing. Winter glazing is a more universal phenomenon because it comprises a frost winter glazing that could be seen during rainfalls or drizzle in temperatures close to $0^{\circ} \mathrm{C}(30-45 \%$ of cases) or a phenomenon of post-snow slippery roads that appears as a result of hardening of the snow which has not been removed (55-70\% of cases). The costs of snow removal considerably vary in the particular years. They exceeded $40 \%$ in the years $1969 / 70,1978 / 79,1981 / 82,1986 / 87$ and amounted only to $20-25 \%$ in the seasons $1972 / 73,1974 / 75,1988 / 89$ and $1989 / 90$.

The impassableness of roads is caused mainly by excessive snowfalls. The whole road network was mostly impassable in the period 1969/70 - 1989/90, in the five winter seasons: $1969 / 70,1978 / 79,1981 / 82,1985 / 86$ and 1986/87. In these seasons, the total length of impassable segments of the roads each day in the whole season, in relation to the general length of roads planned to be made snow-free, exceeded 50\%. Although the most snowy winter occurred in the season 1969/70, the incomparable to the remaining seasons was only the season of 1978/79, when a sum of registered impassable segments exceeded almost 8 times the length of roads in the country (i.e. $105,450 \mathrm{~km}$ ). In the seasons $1970 / 71,1973 / 74,1976 / 77$ the total segments amounted to $30-50 \%$ of the length of roads in the country that were planned to be made snow-free.

In the years 1969/70-1989/90, in ten winter seasons some fragments of the roads of the 1st category of snow-removal were impassable, but those were rela- 
tively short fragments (except for seasons 1978/79 and 1981/82) and they were made passable within 1-3 days. Some segments of the roads of the 2 nd category were impassable during all seasons except $1974 / 75$ and 1988/89. The greatest percentage of the impassable roads of the 3rd category is an effect of the interventional character of snow removal by the road services after the roads of the higher class were made passable.

In the years $1972 / 73-1989 / 90$ a road of the 1st category was impassable on the average 3.5 days in the winter season, a road of the 2 nd category 10.8 days, and a road of the 3rd category 31.2 days. Those were however, relatively small segments impassable during every day: $0.20 \%$ of roads of the 1st category, $0.77 \%$ of roads of the 2 nd category, and $1.40 \%$ of roads of 3 rd category. This characteristic of road traffic disruption reveals also the unique character of the winter season 1978/79. Only in this season higher percentages than the all quoted above average data appeared: roads of the 1st category were impassable throughout 13 days (2.48\% during the day) roads of the 2 nd category 44 days $(6.73 \%)$, and roads of the 3 rd category 80 days $(12.59 \%)$. It is estimated that during that winter in January and February 1979, an access to $1 / 3$ of the country's area was difficult. The day of national disaster was 18 February when almost $50 \%$ of the country's area was hardly accessible $(80 \%$ in the North-Eastern Poland). Economic losses being the effect of impassable roads, including the cost of snow removal, are estimated at $3.7 \%$ of the value of the GNP in the $1979^{2}$. However, these losses do not comprise losses incurred due to absence at work, lateness, tiredness, closed shops and schools. In January and February 1979 , about 350 thousand of people daily could not come to their work by buses. Altogether, 436 passanger trains were cancelled, and among trains on the track $30 \%$ were delayed, the average time being 50 minutes.

The press publications are one of the sources of information often not subject to regular registration. To identify intensity of disturbances in the road transportation in the social perception, analysis was made of the reports about closed roads, difficulties in the road traffic, breakdowns of vehicles, delays, road accidents in the country in the period November-March in the years 1960/611989/90. This information was published in the daily Życie Warszawy (Warsaw Life). The causes of disruptions were snowfalls (45\%), blizzard (25\%) low temperature or its oscillations around $0^{\circ} \mathrm{C}(30 \%)$. At least cne such report was published in 890 editions of this newspaper (Fig. 2), most of them in the seasons $1962 / 63,1969 / 70,1984 / 85,1986 / 87,1985 / 86,1978 / 79,1982 / 83$ (50-70 editions of the newspaper). According to the meteorological data the most frosty and snowy winters were seasons $1962 / 63,1969 / 70$, and 1978/79. The second class of winters in respect of severity were the seasons $1984 / 85,1985 / 86$ and 1986/87. The press did not devote so much attention (less than 50 editions of the

2 "The winter of the Century" turned into national disaster more painful than the most catastrophic floods. Direct and indirect losses caused by the greatest inundation in the past 30 years (in 1980) are estimated at $1.6 \%$ of the GNP. 


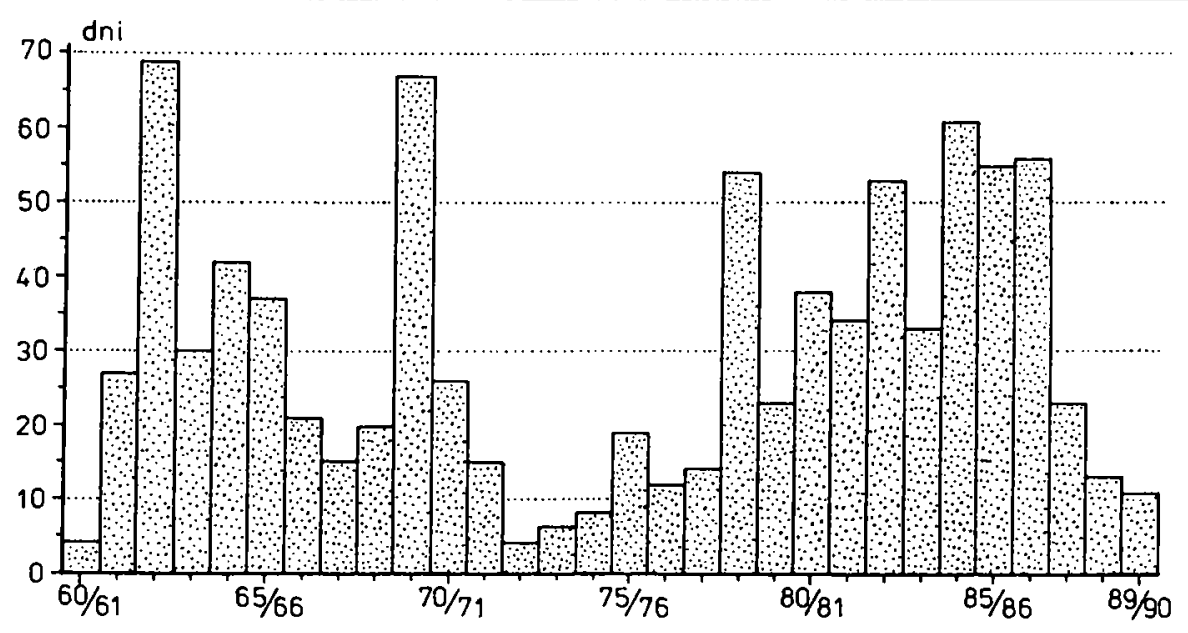

Fig. 2 Number of days during the winter when daily newspaper Życie Warszawy published at least one report about road disruption due to snow and ice in Poland 1960/61-1989/90

newspaper) to the third class of winters $1963 / 64,1964 / 65,1968 / 69,1977 / 78$ and $1981 / 82$, which also appeared less severe in the light of physical characteristics than the six above-mentioned seasons. The season of $1982 / 83$ was even characterized by mild winter, although the phenomenon of glazed frost often appeared. Summing up, it should be said that the relatively high percentage of the road disruptions is reported in the 1980 s (42.4\% newspaper editions) and 1960s (37.3\%) in relation to the $1970 \mathrm{~s}(20.2 \%)$ which were characterized by milder winters, excepting the season of $1978 / 79$.

The higher percentage of reports about road disruptions in the 1980s was more a consequence of limited means for road maintenance and poor condition of the park of vehicles, than of atmospheric conditions. In the 1980s, the intensity of road traffic was on the average over twice as high as in the 1960s, with slightly less frosty and snowy (on the average) winters that were yet more severe than in the decade of the 1970 s, the intensity of road traffic being similar. In the 1980s, (in particular in the frostiest seasons - 1984/85, 1986/87) the number of reports about road traffic disruptions due to vehicles breakdowns increased. Thus this kind of picture can be an effect of objective conditions (vehicle park wear an tear, reduction of outlays for the road maintenance), as well as of "winter theme" taken as a substitutional theme by the press, in the light of the then political situation in the country (particularly 1982/83). It should be emphasized, however, that the press to a considereable extent did not take into account the burdensome winter of 1981/82 (newspaper was not edited in the initial period of martial law) during which the roads were passable to a limited degree like in the 1985/86 and 1986/87 seasons.

The greatest threat to the passable condition of the roads can be observed in the Eastern and only partially Central Poland. But the areas of the most intensive economic activity situated in the Southern and Central Poland suffered most as a consequence of the severe winter only in 1962/63. We may add that the greatest 
financial means for the winter maintenance of roads, mainly state roads, are allocated to the most active regions and, consequently, with the most intensive traffic (Katowice, Warsaw, Cracow, Łódź, Kielce) and not to the regions that are potentially most threatened by the blockade of roads by snow. The more so it would seem that a positive correlation between a good passable state of roads and a great intensity of traffic, should appear. Nevertheless, such a correlation for data of 1984-1990 was not confirmed, and for the roads of the 3rd category the correlation was even negative (preference for the snow removal from the 1st category roads). Among the regions of the great intensity of traffic, mainly the regions of Łodź, Warsaw and Cracow were the ones where the disruptions in road traffic appeared (Fig. 3).

Contrary to the current opinions, in the winter season a number of road accidents decreases. The hard winter conditions force drivers to go slower and to be more careful. There is also some reduction of the intensity of traffic (decrease in the number of transports and fuel rationing in the 1980s). In the years 1975-1989, January and February were characterized by the lowest number of accidents (a relation of a number of accidents in the given month to the monthly average): 0.72 and 0.62 respectively. Analogous indicators for the decade of 1960-1970 amounted to 0.65 and 0.63 respectively and were marked by a little variability regardless of the winter severity. It was surprising that in the years 1975-1989 the lower indicators of the accidents are attribute of the more severe winters $(1979,1985,1986,1987)$, and higher indicators - of the milder winters $(1983,1984,1988,1989)$. It is probably a consequence of limitation of use of private vehicles during a severe winter coupled with rationing of fuel that was often stored for the summer vacation use. But the number of accidents with dead victims was slightly higher in winter than the yearly average ( 14.05 casualities in 100 accidents, while in January 14.56 and in February 14.49). During the winter (1984-1990) the number of accidents depends on the intensity of traffic rather than the length of closed roads. However, there is a positive correlation in the road regions between the number of the accidents with dead victims and the length of impassable fragments of the 3rd category roads (Eastern Poland).

A severe winter is an environmental threat which is underestimated in the awareness of the society because of its rare occurrence and relatively good adaptation of inhabitants to the winter conditions which do not deviate from the average ones. In Poland, it was only the 1978/79 winter that brought disastrous effects. The winters of $1962 / 63$ and $1969 / 70$ were even slightly more severe (the most frosty winter and the most snowy winter in 30 years respectively) but they occurred in dissimilar socio-economic conditions. By the end of the 1970s, a number of engine-driven vehicles was five times as large as in 1960, and intensity of traffic was over twice as high as on the out-of-urban roads. The long period of relatively mild winters in the 1970 s weakened the intensity of preventive activities. Of importance is also the fact of publications of a long-term prognosis in December which forecast a comparatively mild winter in January 1979, and a sudden appearance of the first attack of winter on the New Year's Eve undoubtedly made it difficult for the road service to mobilize means and forces. 

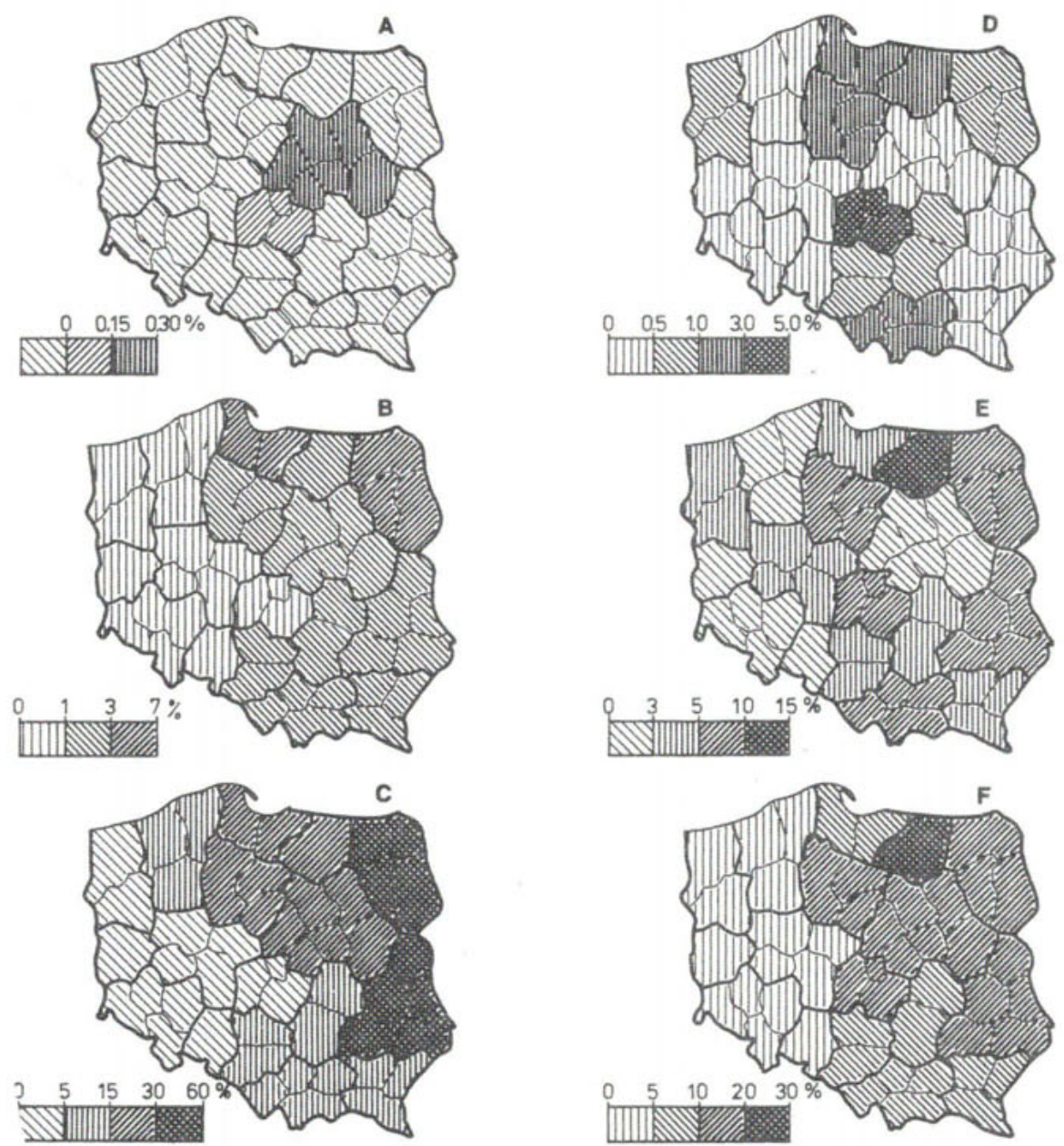

Fig. 3. Average percentage of impassable roads (A - 1st category, B- 2nd category, C - 3rd category) and roads with traffic disruptions (D-1st category, E - 2nd category, F - 3rd category) during the winter seasons 1983/84-1989/90 in Poland

\section{REFERENCES}

Ocena przebiegu prac przy zimowym utrzymaniu drog (The assessment of the course of work for the winter maintenance of roads), Ministry of Transportation, General Directorate of Public Roads, 1971-1990, Warszawa.

Paczos S., 1982, Stosunki termiczne $i$ snieżne zim $w$ Polsce (Thermal and snow characteristics of winters in Poland), UMCS (University of Marie Curie-Skłodowska), Lublin.

Wypadki drogowe w Polsce (Road accidents in Poland), 1975-1989, Headquaters of the State Police, Warszawa. 